\title{
The place of confinement-a question of statistics or ethics?
}

\author{
L I Zander General practitioner, London
}

\section{Editor's note}

The author, a London general practitioner, discusses some of the ethical issues arising from the hospital vs home confinement debate. He suggests that safety is only one factor to be taken into account, and in any case there is evidence that domiciliary confinement may be as safe or safer than hospital confinement. In addition the 'experiential dimension of childbirth' must be considered, as must the wishes of the woman herself. 'We have the responsibility of providing appropriate and unbiased information on which our patients can make well-informed decisions about their own lives'. Moreover, by insisting on virtually total hospital confinement obstetricians may be impairing the ability of their general practitioner colleagues to undertake their own 'holistic' roles.

This paper is based on a talk given to the London Medical Group.

It is generally believed that the practice of medicine is based on the firm foundation of a well developed code of medical ethics. Most members of the profession would claim not only an awareness of its existence but an appreciation of the importance of abiding by its principles. However, as Mr Ian Kennedy indicated in his recent Reith Lectures (I), little instruction, either formal or informal, in ethics is received during medical training, and if curricular time and inclusion in examinations is any indication of the regard with which subjects are held, some anxiety might indeed be justified as to the real concern and degree of consideration that is given to this fundamental aspect of care.

How important, in reality, are medical ethics considered to be? How aware are we in the profession of the ethical dimension of the decisions we take? What place do they occupy in our hierarchy of priorities? What are the implications and likely repercussions if they are disregarded ? The answers to such questions need to be judged by reference to what happens in practice, rather than by considering theoretical models.

The present debate concerning the rights of women to choose their place of confinement provides an interesting and topical opportunity to consider some of these issues.'

The debate concerning domiciliary obstetrics has become the focus of increasing attention in both medical and lay circles, and it is important to analyse why this might be the case. It is not just a discussion concerning the comparative merits or demerits of a particular form of treatment or management. Its importance lies in the fact that it touches on some of the most fundamental questions concerning not just obstetrics but that of the practice of medicine itself; questions such as what to do we mean by health, illness and disease and what requirements do our answers demand of the profession? What is the nature of the doctor/patient relationship? What role has the consumer in medical care decision-making ? How is the clinician to base his actions on scientific objectivity while at the same time being sensitive to the personal needs of the individual patient ? What is the relationship between the need for intraprofessional responsibility to colleagues, and the responsibility of the profession to society? All these facets of medical practice are involved in the issue under consideration.

The essence of the debate concerning the 'Place of Birth', can be summarised as follows: On one hand there is the view of the obstetric establishment which states a clear intention to aim for 100 per cent hospital confinements; while on the other, there are individuals both within the medical profession and outside who feel that women should be allowed to have their confinements at the place of their choice (assuming there are no overriding contraindications) until such time as it has been shown that this is a course of action that is either inadvisable or unacceptable on medical, social or economic grounds.

Let us consider some of the ethical dilemmas highlighted by these opposing views.

\section{What is good obstetric care?}

When considering the validity or otherwise of maintaining the possibility for home deliveries, it is necessary to establish generally acceptable criteria which can provide a framework within which to make such a judgment. These might be summarised as follows:

I) To achieve a confinement that will result in a healthy mother having a healthy baby with the minimum of avoidable complications-an issue of safety. 
2) That the mother will be helped to feel emotionally satisfied and fulfilled by the birth of her baby and that it will strengthen the bond between husband and wife and other members of the family by allowing them to share this very personal experience-the experiential aspect or quality of childbirth.

3) That the management of the confinement makes optimal use of available resources.

\section{Safety and the role of statistics}

When considering the value of statistics one needs to bear in mind:

a) How accurate and valid are they?

b) How are they to be used?

Those arguing that all women should be confined in hospital irrespective of their stated wish base their case on the understandable belief that it is a safer form of obstetric practice. They point to the steady decline in the neonatal mortality figures which has occurred at the same time as the fall in the number of home confinements. The critical question, however, is whether these statistics are causally related or purely coincidental and due to quite other factors, eg social changes. Scientifically objective study of the statistical evidence available should be able to help differentiate these two alternative possibilities. Interestingly enough, very strong evidence has been produced which suggests that the results of domiciliary confinements following good antenatal care may in fact be not only as good but even better than hospital delivery for certain groups of women (2), (3). The possible reasons for this, although at first perhaps surprising, are not difficult to understand in view of the increasing adoption of an 'active management' approach to labour which takes place in many obstetric units, and also because new techniques considered safe in the centres of excellence in which they are developed may give rise to complications when introduced to hospitals less well endowed with adequate equipment and skilled staff. Having based their whole argument on one of safety, the reluctance of the profession to consider this evidence objectively-without refuting it by statistical argument-suggests that their decision has been made on preconceived assumptions which they are not willing to reconsider in the light of available evidence. The fact that this reluctance might cast doubt in some minds as to whether the reasons for it stem principally from a concern for patient care, or principally from intraprofessional self-interest, has ethical implications of considerable significance.

\section{The experiential dimension of childbirth}

Those requesting home rather than hospital confinements do so either because of a positive desire to have the experience of childbirth in the setting of their own homes, or for the more negative reasof of not wishing to avail themselves of the service provided by the particular hospital of their neight bourhood. The reasons for such a choice wit frequently include such factors as the informat conduct of the labour, the absence of any particulat routines to which the mother feels she must accommodate her wishes and actions, the sense relaxation engendered by being in familiar suf roundings often with her husband and other ments bers of the family present, the continuous attendang of a single midwife who is often the person with whom she has already formed a relationship during antenatal care, the presence of her own family doctor during at least part of the labour, and the fact that the unsuitability of home surrounding for medical intervention tends to discourage such interference. Women making such a request cannọ be considered as representatives of a lunatic fring members of a group of self-motivated, egotistie, dominating, middle class, National Childbirth Trust trained mothers, who for some reason seem to engender such antagonism in members of oui profession. Rather, they come from all classes an demonstrate many valued characteristics of pe sonality such as independence, caring, and a desire to enjoy fully one of life's major experiences.

\section{Principles and the clinician's response}

A general practitioner defined as 'a doctor provides personal and continuing care for individuat and families' is enjoined to 'make his diagnosis i physical, psychological and social terms' Bearing this in mind how are we to respond to the wishes of our patients when confronted in ou consulting room with a request for home delivery In such a situation, one is removed from the safer of decision-making by statistics, and is exposed to the hazardous and challenging situation of having to make up one's mind on a course of action by endeavouring to achieve an appropriate balance between often non-comparable variables. As generi practitioners we talk about ourselves as person physicians, and much of our vocational training is based on the concept of holistic medicines patient-orientationed as opposed to disease-orien tated. If these concepts are to mean anything surely they behove us to be exceedingly sensitive to and aware of, the wishes of our patients. If there is doubt about safety, and clearly there is always thee possibility of something unexpected going wrong that needs to be explained. We have the responsibility of providing appropriate and unbiasel information on which our patients can make wein informed decisions about their own lives. If he is to provide appropriate advice, the clinician wi need to focus on the concerns and wishes of his patient, to be sensitive to her ideas. For him to undertake this role, he will need to establish a meang 
of communication that will allow her to share her hopes and fears with him. His reaction and response to her demands and the value he ascribes to her views will be a reflection of the true nature of the doctor/patient relationship.

The characteristics of the specialist obstetrician contrast most interestingly in a number of significant respects from that of the general practitioner. His contact with the patient starts at the time of the pregnancy and ends shortly after the completion of labour. $\mathrm{He}$ is not concerned with her general care, let alone with that of her family, and it is unlikely that he will manage to establish a personal relationship with her, there being so little opportunity for continuity of care in the normal hospital antenatal routine. His involvement with deliveries is likely to be rather minimal and then probably only when complications are present, so that his whole orientation will inevitably become geared towards pathology and its correction. Finally, his 'territory' is the hospital and the mother's home will be an alien setting. Is it surprising therefore that he is likely to be unsupportive to the idea of domiciliary confinements ? Not only is it a form of care that is unknown to him but by its emphasis on noninterference and with its absence of technical monitoring facilities it might be said to challenge and even threaten the principles on which his own form of management is based. Once this is understood, it is easier to comprehend, although not to condone, the rejection of women's requests to deliver at home. Rational decisions are not always easy when one's beliefs are being challenged. This raises a fundamentally important question of how decisionmaking about obstetric care is to be undertaken. Is it appropriate or even ethical to allow this to remain almost solely in the hands of those who by virtue of making obstetrics their specialty have acquired a perspective that, although highly advanced scientifically, has restricted their view of the human experience of childbirth? How can we ensure the appropriate input from such relevant additional perspectives as those of the generalist, the midwife, the psychologist, and, especially those of the mothers themselves ?

\section{The relationship to professional colleagues}

The concept of the health care team is based on the principle of an interdependence between professional colleagues. If this is to function optimally it is important it should be based on mutual understanding and appreciation of each other's role. If a general practitioner is to undertake domiciliary confinements, he will need to be confident of the support and acceptance of his obstetric colleagues. It is necessary that they understand that his action is based not on a personal wish to 'dabble' in a little bit of obstetrics out 'on the district', but rather on the desire to provide for the individual needs and wishes of his patients as he perceives them in his role as their personal physician. By rejecting home deliveries and basing his opinions on grounds of principle, the hospital-based obstetrician is in a position to remove support from his community-based colleagues and thereby make their task very much more difficult, if not impossible. Such a course of action is seen all too frequently and it is not surprising that a direct result is the increasing reluctance of practitioners to provide this type of care, and the support for community midwives, that their patients are requesting and which on present evidence have full justification in receiving. This situation focuses attention on the question of what are the responsibilities that we have within the profession to consider the effects that our decisions might have on colleagues' ability to fulfil their own roles.

\section{The relationship of the profession to society}

One important factor which should not be overlooked is that whatever the profession decides, the patient still has the right and the capability to follow that course of action which she feels appropriate. In some parts of the United States significant numbers of women are now having their babies without any recourse to medical care, indicating that the obstetric practice provided is in some way unacceptable to the women concerned. It is inevitable that the consumer voice will become increasingly heard on the medical stage and unless the profession clearly demonstrates willingness and ability not only to listen to but also to hear what is being said, there is a danger that the relationship between doctors and patients will become increasingly adversarial, rather than one based upon partnership in a common enterprise. If conflict is to be avoided it is essential that we in the profession are seen to be fully honest with our patients with regard to the reasons for our decisions, and more importantly that we give clear indication to them of the high regard in which we hold their views and values. It is not in the area of clinical care but rather by clearly demonstrating an adherence to our code of ethics that we will be judged and the developing sense of antagonism averted.

\section{References}

(I) Kennedy I. The Reith Lectures-Unmasking medicine. The Listener 1980 Nov 6-Dec II: 600-604; 64I-644; 677-679; 713-715; 745-748; 777-780.

(2) Tew M. Home versus Hospital Confinement: the statistics. Update 1979; 1317-1322.

(3) Kloosterman G J. The Dutch system of home births. In: Kitzinger and Davis, eds, The Place of Birth. Oxford University Press, 1978.

(4) The Royal College of General Practitioners. The future general practitioner. In: Learning and Teaching. London, BMA House, 1972. 